\title{
ASSESSMENT OF SERUM ALLERGEN-SPECIFIC IgE LEVELS IN HORSES WITH SEASONAL ALLERGIC DERMATITIS AND RECURRENT AIRWAY OBSTRUCTION IN SPAIN
}

\author{
Diana MARTeles, Laura Odriozola, María Teresa Verde, Tomás Conde \\ and Antonio FERNÁNDEZ \\ Animal Pathology Department, Veterinary Faculty, Zaragoza University, \\ Miguel Servet 177, 50013 Zaragoza, Spain
}

(Received 16 April 2018; accepted 20 November 2018)

\begin{abstract}
Allergic conditions are prevalent equine diseases that can be diagnosed by clinical examination alone, but definitive diagnosis is more likely with laboratory testing. The ELISA Allercept ${ }^{\circ}$ test was used to analyse the serum samples of 73 horses with allergic diseases. Sixty-one horses (83.5\%) had allergen-specific IgE levels $\geq 150$ ELISA Units (EU), the cut-off defined by the assay. Fifty-four horses had allergic dermatitis (AD) with high IgE levels to Tyrophagus putrescentiae (51.9\%), Rumex crispus (48.1\%), Tabanus (46.3\%) and Dermatophagoides farinae/ D. pteronyssinus $(40.7 \%)$. Seven horses with recurrent airway obstruction (RAO) had a high prevalence of T. putrescentiae (85.7\%), followed by that of Acarus siro $(57.1 \%)$ and $D$. farinae/D. pteronyssinus $(57.1 \%)$. Horses affected with RAO had more positive reactions to mites $(2.22 \pm 0.84)$ than did horses with AD $(1.51 \pm 0.61, \mathrm{P}<0.05)$. A strong correlation of serum allergen-specific IgE level was found between Culex tarsalis and Stomoxys $(\mathrm{r}=0.943)$ and between Dactylis glomerata and both Secale cereale $(\mathrm{r}=0.79)$ and $R$. crispus $(\mathrm{r}=0.696)$. These results indicate that among horses with allergic diseases in Spain, ELISA tests demonstrated a high prevalence of serum allergen-specific IgE in response to mites. Our study emphasises the importance of laboratory testing and updating allergy panels to improve the likelihood of a definitive diagnosis and the identification of allergens that should be included in allergic disease treatment.
\end{abstract}

Key words: Horse, allergen-specific IgE, diagnosis, allergic diseases

Allergic diseases are common in horses worldwide, with a prevalence ranging from 0 to $74 \%$ depending on the area (Grevenhof et al., 2007; Wilkołek et al., 2014; Mueller et al., 2016). Atopic dermatitis is a genetically programmed hypersensitivity of the skin to environmental allergens that results in increased IgE production, whereas insect bite hypersensitivity (IBH) is a recurrent allergic skin disease caused mainly by Culicoides spp. (Scott and Miller, 2011; Schaf-

*Corresponding author; E-mail: afmedica@unizar.es; Phone: 0034 (976) 761-000/Ext. 1574; Fax: 0034 (976) 761-612 
fartzik et al., 2012). These diseases are difficult to distinguish clinically, and veterinarians make most diagnoses after obtaining a complete medical history and performing a clinical examination. Intradermal skin tests with multiple (i.e., up to 61) allergens, usually performed on the neck, can further identify specific causal agents (Lorch et al., 2001b; Lebis et al., 2002; Morgan et al., 2007; Rendle et al., 2010; Roberts et al., 2014). However, this technique can be problematic because the animal needs to be sedated and interpretation of the results can be difficult. In addition, false-positive reactions have been reported in healthy horses without disease (Lorch et al., 2001a; Baxter and Vogelnest, 2008), which have irritant reactions and cross-reactions because of previous allergen exposure (Lebis et al., 2002; Scott and Miller, 2011). False-negative reactions can also result from low serum allergen concentrations or the concurrent administration of medications that inhibit IgE reactions. Recent improvements in ELISA tests have increased the detection accuracy of allergen-specific IgE levels (Roberts et al., 2014; Wilkołek et al., 2014; Niedzwiedz et al., 2015).

Equine allergic diseases have been studied in many European countries (Lebis et al., 2002; Grevenhof et al., 2007; Raskova and Citek et al., 2013; Wilkołek et al., 2014) and the United States (Lorch et al., 2001a) but not in Spain. Allergic diseases have recently emerged in both human and veterinary medicine, and dogs, cats and horses are becoming increasingly allergic to pollens (Mueller et al., 2016). Environmental allergens, including insects, differ between geographical areas, so local studies are required to identify the prevalence of aeroallergens and insect species implicated in horses with allergic diseases. The goal of this study was to identify the aeroallergens and insect-specific allergens associated with horses in Spain with allergic dermatitis (AD) or recurrent airway obstruction (RAO) based on a commercially available ELISA test for serum allergen-specific IgE.

\section{Materials and methods}

\section{Serum samples and inclusion criteria}

Informed consent was obtained from both horse owners and veterinarians. The study was carried out between summer 2013 and spring 2015. Serum samples from 73 horses with clinical signs of allergic disease were sent by Spanish veterinarians to the Animal Pathology Department, Veterinary Faculty, Zaragoza University, Spain. A routine haematological analysis that included red blood cell (RBC) and white blood cell (WBC) counts and haematocrit and haemoglobin determination was performed for all horses. No difference in the haematological analysis results was observed, except for an increase in the eosinophil count in some animals. The inclusion criteria for RAO were exercise intolerance, laboured breathing at rest, and increased lung sounds with or without adventitious sounds on auscultation. Bronchoalveolar lavage was performed, and a neutrophil 
concentration $>25 \%$ was indicative of RAO. The horses with pruritus were diagnosed with a dermatological protocol procedure that included the scraping of the lesions to detect mites and lice and trichogram and fungal culture on Sabouraud agar to detect dermatophytes. For horses with AD, the criteria were a history of seasonal pruritus and characteristic pruritic skin lesions around the mane or tail or on the body. The exclusion criteria for both groups included systemic infection (fever, leukocytosis), external or internal parasites, and other chronic diseases.

\section{Determination of allergen-specific IgE}

Frozen serum samples were shipped on ice to Laboratorios Diavet (Leganés, Madrid, Spain) to be tested. Allergen-specific IgE was analysed by a noncompetitive solid-phase ELISA with an Allercept ${ }^{\circ}$ system that used a highaffinity $\operatorname{IgE}$ receptor. The results were expressed in ELISA Units (EU) based on optical density values determined at $405 \mathrm{~nm}$, with $\geq 150 \mathrm{EU}$ considered positive, a cut-off determined by Heska AG (Fribourg, Switzerland). All samples were tested against 24 aeroallergens and six insects (Table 1).

\section{Statistical analysis}

Statistical analysis was performed using SPSS 22 software (IBM Corp., Armonk, USA). Horses were grouped based on their AD or RAO clinical diagnosis, age [i.e., young ( $\leq 6$ years) or adult ( $>6$ years)], breed [i.e., Pura Raza Española (PRE) or crossbreed], and sex (i.e., stallion, female, or gelding). The Kolmogorov-Smirnov test was used to evaluate the normal distribution of serum allergen-specific IgE. A non-parametric Mann-Whitney test was used to compare AD or RAO allergen-specific IgE serum levels. Odds ratios (ORs) were used to assess the association of the horses within each group with groups of allergens that were present or absent. The correlation between the serum allergenspecific IgE levels was determined with a Spearman rank correlation test. The adjusted value for significance was $\mathrm{P}<0.05$.

\section{Results}

Of the samples from the 73 horses clinically diagnosed with AD or RAO, $12(16.5 \%)$ were negative for allergen-specific $\operatorname{IgE}(\leq 150 \mathrm{EU})$, and $61(83.5 \%)$ were positive. Of these positive horses, $54(88.5 \%)$ had a clinical diagnosis of $\mathrm{AD}$, and seven $(11.5 \%)$ had a clinical diagnosis of RAO.

Table 1 shows the number and percentage of horses positive for each allergen and the serum IgE levels in each case, with $70.5 \%$ of the horses testing positive for mites, mainly $T$. putrescentiae $(55.7 \%)$. Serum allergen-specific IgE 
in response to insects was also prevalent (67.2\%), with specificity for Tabanus (44.3\%) being the most frequent. Allergens to weeds were found in $49.2 \%$ of the horses, with Rumex crispus $(45.9 \%)$ being the most prevalent. Twenty horses $(32.8 \%)$ were positive for grass allergens, all showing allergens for Dactylis glomerata. Nine horses $(14.8 \%)$ had serum allergens specific for trees. Only five serum samples $(8.2 \%)$ were positive for allergens from the mould group. The odds ratio analysis showed that horses with RAO were 8.95 times more likely to be positive for $A$. siro $(\mathrm{P}=0.016 ; 95 \%$ CI 1.6-48.7) than were horses with AD. No other association was found with either AD or RAO.

Table 2 shows the number of positive reactions to different allergen groups. The mean number of mites that caused a positive reaction was significantly higher in RAO-affected horses than in AD-affected animals $(\mathrm{P}<0.05)$.

Allergic diseases were diagnosed most frequently in the spring $(25$ positive horses, $41 \%$ ), followed by autumn (19 horses, $31.1 \%$ ) and summer (17 horses, 27.9\%). Twenty-four mares (39.3\%), 10 stallions (16.4\%) and 27 geldings $(44.3 \%)$ were used in this study. No significant association was observed with sex $(\mathrm{P}>0.05)$. More adult horses $(40,65.6 \%)$ than young horses $(21,34.4 \%)$ were included in the study. The young animals were 3.71 times more likely to have an allergic reaction to $R$. crispus pollen $(\mathrm{P}=0.03 ; 95 \% \mathrm{CI} 1.22-11.3)$ than were the adults. PRE was the main pure breed represented (20 horses, $32.8 \%$ ) and was 3.22 times more likely to respond to $R$. crispus $(\mathrm{P}=0.036 ; 95 \% \mathrm{CI}$ 1.05-9.8) than were the other breeds.

Table 3 shows that the correlation between the serum levels of allergenspecific IgE in response to insects was high, and the correlation found between the serum levels of Culex tarsalis and Stomoxys was the strongest. The correlations between the environmental allergens were lower, and only D. glomerata was positively correlated with $S$. cereale $(\mathrm{r}=0.79, \mathrm{p}=0.008), R$. crispus $(\mathrm{r}=$ $0.696, p=0.009)$ and $T$. putrescentiae $(r=0.798, P=0.011)$. Only one significant correlation was found in the mite group between $D$. farinae/D. pteronyssinus and T. putrescentiae $(\mathrm{r}=0.598, \mathrm{P}=0.013)$.

\section{Discussion}

The Allercept ${ }^{\odot}$ test has been widely used for allergy diagnosis and for comparative investigations with intradermal testing in horses with AD or RAO (Frey et al., 2008; Tahon et al., 2009; Roberts et al., 2014; Niedzwiedz et al., 2015). Veterinarians need to identify to which allergens the horses are sensitive to perform hyposensitisation therapy against those allergens that are responsible. Immunotherapy is the present goal of treatments for allergic diseases (Scott and Miller, 2011; Schaffartzik et al., 2012), and most investigations are directed towards that goal. 
Table 1

Number and frequency of positive results determined by Allercept ${ }^{\circ}$ ELISA for serum allergen-specific IgE $(\geq 150 \mathrm{EU})$ in 61 horses with allergic dermatitis (AD) and recurrent airway obstruction (RAO)

\begin{tabular}{|c|c|c|c|c|c|}
\hline Allergen & $\begin{array}{c}\text { Allergic } \\
\text { horses } \\
(n=61) \\
\text { Number } \\
(\%)\end{array}$ & $\begin{array}{c}\text { AD } \\
(\mathrm{n}=54) \\
\text { Number } \\
(\%)\end{array}$ & $\begin{array}{c}\text { Mean } \\
\text { IgE levels } \\
\text { (range) }\end{array}$ & $\begin{array}{c}\text { RAO } \\
(\mathrm{n}=7) \\
\text { Number } \\
(\%)\end{array}$ & $\begin{array}{c}\text { Mean } \\
\text { IgE levels } \\
\text { (range) }\end{array}$ \\
\hline Grasses & $20(32.8)$ & & & & \\
\hline Dactylis glomerata & $20(32.8)$ & $18(33.3)$ & $541(155-2161)$ & $2(28.6)$ & $625(597-654)$ \\
\hline Plehum pratense & $3(4.9)$ & $3(5.5)$ & $238(186-315)$ & $0(0)$ & - \\
\hline Secale cereale & $12(19.6)$ & $11(20.3)$ & $299(151-558)$ & $1(14.3)$ & $1103(1103-1103)$ \\
\hline Weeds & $30(49.2)$ & & & & \\
\hline Artemisia vulgaris & $0(0)$ & $0(0)$ & - & $0(0)$ & - \\
\hline Chenopodium spp & $3(4.9)$ & $3(5.5)$ & $402(152-680)$ & $0(0)$ & - \\
\hline Plantago lanceolata & $9(14.8)$ & $8(14.8)$ & $272(156-526)$ & $1(14.3)$ & $161(161-161)$ \\
\hline Urtica dioica & $2(3.3)$ & $2(3.7)$ & $167(162-173)$ & $0(0)$ & - \\
\hline Rumex crispus & $28(45.9)$ & $26(48.1)$ & $603(152-2314)$ & $2(28.6)$ & $238(172-304)$ \\
\hline Trees & $9(14.8)$ & & & & \\
\hline Betula alba & $4(6.6)$ & $4(7.4)$ & $202(160-243)$ & $0(0)$ & - \\
\hline Salix caprea & $4(6.6)$ & $4(7.4)$ & $234(204-269)$ & $0(0)$ & - \\
\hline Corylus spp & $3(4.9)$ & $3(5.5)$ & $194(161-224)$ & $0(0)$ & - \\
\hline Fagus sylvatica & $5(8.2)$ & $5(9.3)$ & $251(185-369)$ & $0(0)$ & - \\
\hline Moulds & $5(8.2)$ & & & & \\
\hline Alternaria alternata & $2(3.4)$ & $2(3.7)$ & $186(167-205)$ & $0(0)$ & - \\
\hline Aspergillus fumigatus & $0(0)$ & $0(0)$ & - & $0(0)$ & - \\
\hline Cladosporium herbarum & $0(0)$ & $0(0)$ & - & $0(0)$ & - \\
\hline Epicoccum nigrum & $0(0)$ & $0(0)$ & - & $0(0)$ & - \\
\hline Helmintosporium halodes & $0(0)$ & $0(0)$ & - & $0(0)$ & - \\
\hline Penicillium notatum & $1(1.6)$ & $1(1.9)$ & $191(191-191)$ & $0(0)$ & - \\
\hline Fusarium culmorum & $0(0)$ & $0(0)$ & - & $0(0)$ & - \\
\hline Ustilago tritici & $1(1.6)$ & $1(1.9)$ & $238(238-238)$ & $0(0)$ & - \\
\hline Rhizopus nigricans & $1(1.6)$ & $1(1.9)$ & $155(155-155)$ & $0(0)$ & - \\
\hline Mites & $43(70.5)$ & & & & \\
\hline Acarus siro & $11(18)$ & $7(13)$ & $307(165-481)$ & $4(57.1)$ & $265(165-491)$ \\
\hline D. farinae/D. pteronyssinus & $26(42.6)$ & $22(40.7)$ & $322(153-1515)$ & $4(57.1)$ & $366(169-778)$ \\
\hline Tyrophagus putrescentiae & $34(55.7)$ & $28(51.9)$ & $483(155-3165)$ & $6(85.7)$ & $648(198-1285)$ \\
\hline Insects & $41(67.2)$ & & & & \\
\hline Simulium spp. & $12(19.7)$ & $10(19)$ & 298 (156-639) & $2(28.6)$ & $336(240-433)$ \\
\hline Culex tarsalis & $22(36)$ & $20(37)$ & $280(152-732)$ & $2(28.6)$ & $393(266-521)$ \\
\hline Tabanus & $27(44.3)$ & $25(46.3)$ & $395(154-2420)$ & $2(28.6)$ & $414(167-662)$ \\
\hline Stomoxys & $10(16.4)$ & $9(16.7)$ & $303(160-627)$ & $1(14.3)$ & $352(352-352)$ \\
\hline Culicoides spp. & $22(36)$ & $20(37)$ & $315(151-1180)$ & $2(28.6)$ & $290(261-320)$ \\
\hline Blatella germanica & $14(23)$ & $13(24)$ & $287(164-751)$ & $1(14.3)$ & $242(242-242)$ \\
\hline
\end{tabular}

Dermatophagoides farinae/Dermatophagoides pteronyssinus $=$ D. farinae/D. pteronyssinus; Mean values and ranges in serum IgE are expressed in ELISA Units (EU) 
Table 2

Number of positive reactions in each group of allergens in 61 horses with allergic dermatitis (AD) and recurrent airway obstruction (RAO) by Allercept ${ }^{\circ}$ ELISA

\begin{tabular}{llll}
\hline & \multicolumn{1}{c}{ AD } & RAO & P value \\
\hline Grasses & $1.78 \pm 0.73$ & $1.5 \pm 0.71$ & 0.659 \\
Weeds & $1.53 \pm 0.74$ & $1.5 \pm 0.71$ & 0.739 \\
Trees & $1.78 \pm 1.09$ & - & 0.999 \\
Moulds & $1.0 \pm 0.0$ & - & 0.999 \\
Mites & $1.51 \pm 0.61$ & $2.33 \pm 0.82$ & 0.029 \\
Aeroallergens & $3.24 \pm 2.25$ & $3.33 \pm 1.03$ & 0.465 \\
Insects & $2.62 \pm 1.4$ & $2 \pm 2.35$ & 0.188 \\
All allergens & $4.56 \pm 2.87$ & $4.28 \pm 3.15$ & 0.579 \\
\hline
\end{tabular}

Aeroallergens are sum of grasses, weeds, trees, moulds and mites.

Data are expressed as means \pm standard deviation (SD)

Table 3

Correlation between serum allergen-specific IgE levels ( $\geq 150 \mathrm{EU})$ and insects of the Allercept ${ }^{\mathcal{O}}$ ELISA panel

\begin{tabular}{llllll}
\hline & Simulium & $\begin{array}{c}\text { Culex } \\
\text { tarsalis }\end{array}$ & Tabanus & Stomoxys & Culicoides $\begin{array}{c}\text { Blatella } \\
\text { germanica }\end{array}$ \\
\hline Simulium & 1 & & & & \\
Culex tarsalis & 0.717 & 1 & & & \\
Tabanus & 0.042 & & & & \\
& 0.6 & 0.765 & 1 & & \\
Stomoxys & 0.09 & 0.004 & & & \\
& 0.881 & 0.943 & 0.893 & 1 & \\
Culicoides & 0.017 & 0.035 & 0.028 & & \\
& 0.64 & 0.64 & 0.864 & 0.548 & 1 \\
Blatella germanica & 0.011 & 0.021 & 0.002 & 0.147 & \\
& 0.6 & -0.07 & 0.764 & 0.41 & 0.221 \\
& 0.18 & 0.861 & 0.008 & 0.488 & 0.532 \\
\hline
\end{tabular}

Pearson's correlation coefficient (r) and statistical significance (P value) are shown

The results showed that 12 horses were negative for allergen-specific IgE. Probably, as it occurs in humans and dogs, some horses may present clinical signs of atopy without having serum levels of allergen-specific IgE (Mueller et al., 2016, 2018). In these negative cases where horses presented clinical signs of atopic dermatitis, we could consider these conditions to be 'intrinsic atopy' or 'atopic-like dermatitis', as has been described in dogs and humans. In other words, the horses could be positive for other allergens not included in the equine 
allergy panel used in Spain at present. Additionally, the turnover of serum $\operatorname{IgE}$ is very quick (Morgan et al., 2007) and this may explain why some animals are not detected as positive.

The majority of studies on the prevalence of allergic diseases have been conducted on IBH because it is the main cutaneous allergy diagnosed in horses. For instance, in a study conducted in the Czech Republic, Raskova and Citek (2013) found a $28 \%$ incidence in the offspring based on the occurrence of typical skin lesions seen by veterinarians. In some areas of the Netherlands, Grevenhof et al. (2007) found the prevalence of IBH to be $71.4 \%$. However, such research may overestimate the incidence of allergic diseases. IBH can be misdiagnosed as atopy because these two conditions may be indistinguishable clinically or may occur in the same animal (Rendle et al., 2010; Scott and Miller, 2011). In some cases, horses diagnosed with IBH may be hypersensitive to other allergens as well as to other insects (Rendle et al., 2010; Schaffartzik et al., 2012). Geographic areas that have different vegetation, climate, latitude and altitude can also complicate the comparisons of allergens and insects with other studies performed in northern Europe or the United States. In our study, the majority of horses came from southern Spain, which has a Mediterranean climate and whose plants and insects differ from those in northern Europe. In the Mediterranean area, pollens from trees such as olive, cypress and holm oak, which cause noteworthy allergic reactions in humans, are predominant (D'Amato et al., 2007), and we believe that this class of allergens should be included in the allergy panel for the Mediterranean area.

In our study, no significant reaction to tree pollens and moulds was found, which was similar to the results obtained in other European countries. For example, only $2 \%$ of horses have been shown to be positive for mixed moulds in southern England (Rendle et al., 2010); in Poland, Niedzwiedz et al. (2015) found no serum allergen-specific IgE to moulds in seven RAO-affected horses. The composition of the allergen can cause errors because the crude allergen preparations used in the ELISA (Morgan et al., 2007) compete with the IgG antibodies and induce false-positive results. However, a more recent paper (Niedzwiedz et al., 2015) has reported that the serum allergen-specific IgE levels in RAO-affected horses can be used to identify the cause of sensitivity in susceptible horses using an Allercept ${ }^{\odot}$ analysis, as we did in our study, with similar results. Nevertheless, if veterinarians take a complete history and perform a detailed clinical examination for making a tentative diagnosis, the specificity of FceR1 $\alpha$-based ELISA may be useful for documenting the lack of hypersensitivity to a selected allergen group (Lorch et al., 2001a).

In our study, RAO-affected horses had more positive reactions to mites than did AD-affected horses. Lorch et al. (2001b) found positive intradermal reactions to three or more allergens, while Rendle et al. (2010) reported a mean of 5.8 positive reactions in horses with atopic dermatitis. This high number of posi- 
tive reactions may be due to cross-reactions among different allergen types, similar to those observed between mites and other allergens (Saridomichelakis et al., 2008). The high prevalence of mite allergens found in this work and in other studies (Tahon et al., 2009; Wilkołek et al., 2014; Niedzwiedz et al., 2015) using allergen-specific IgE may be due to the pellets and grains used in horse feed that contain large amounts of forage mites (Tahon et al., 2009). A high infestation by Tyrophagus and Acarus has been demonstrated in the microenvironment of individual horse stalls, in straw bedding used indoors and in round hay bales (Roberts et al., 2014). The horses in our study generally had straw bedding and were given pelleted feed, so they most likely had early, ongoing contact with the mites, which placed them at risk of developing subclinical disease because of the frequent exposure.

RAO is caused by exposure to airborne organic dust containing many different agents, and A. fumigatus has been shown to be an important aetiological agent (Rendle et al., 2010; Mueller et al., 2016, 2018). However, in our study no allergen-specific IgE to moulds was detected by ELISA, in contrast with other studies (Frey et al., 2008; Tahon et al., 2009; Niedzwiedz et al., 2015). Fungal spores need high temperatures and humidity, which increase the total pollen and mould counts. Wet weather with a high concentration of fungal spores is not as common in southern Spain as in other biogeographic regions in Europe (D'Amato et al., 2007). These results also indicate differences in horse husbandry and management because high serum IgE levels in response to moulds have been observed in stabled horses in northern Europe (Eder et al., 2001). Because southern Spain has year-round warm weather, horses here spend most of their time outdoors with presumably less contact with fungal spores. The lack of positive results for most moulds found in our and other studies (Frey et al., 2008; Tahon et al., 2009; Niedzwiedz et al., 2015) and the strong correlation found between serum allergen-specific IgE levels and fungal species (Eder et al., 2000) suggest that the equine allergy panel might be modified to reduce the number of mould allergens.

In our study, young horses and PRE horses were more likely to be allergic to the $R$. crispus allergen than other horses. These results are most likely due to the wide distribution of $R$. crispus and the predominance of PRE as the local breed in the southern Iberian Peninsula. The wide variety of horse breeds and crossbreeds in different reports (Wilkołek et al., 2014) and the differences in animal management and environmental conditions (Eder et al., 2001; Grevenhof et al., 2007) probably complicate the influence of breed on equine allergic diseases.

The pollen season and insect activity begin in the spring when, as in Spain (García-Mozo et al., 2010), the rainfall is higher, correlating with the majority of positive results found in our study. Similar distribution patterns have been reported in other studies (Baxter and Vogelnest, 2008; Wilkołek et al., 2014). These results probably reflect the quick turnover of serum IgE (Morgan et al., 2007) 
and the lack of exposure and sensitisation of the horses' immune system because southern Spain does not experience a winter pollen season (García-Mozo et al., 2010).

The reaction to Simulium observed in the IBH-affected horses was attributed to cross-reactivity with Culicoides, both of which express similar allergenic proteins (Schaffartzik et al., 2012; Mueller et al., 2016). The strong positive correlation found in serum allergen-specific $\operatorname{IgE}$ in the present study was also observed by Eder et al. (2000) in horses affected with chronic bronchitis caused by moulds and storage mites. These results show that a high crossreactivity between insects, mites and some aeroallergens is possible, probably due to subclinical sensitisation and the high presence of insects and Acari fauna in stables (Roberts et al., 2014). To confirm this hypothesis, further studies are needed to investigate the cross-reactivity among the different allergens included in the equine allergy panel.

In conclusion, our findings indicate that in horses in Spain, there is a strong correlation between $\mathrm{AD}$ and positive serum allergen-specific IgE levels in response to storage mites and insects, as well as between RAO and positive serum allergen-specific IgE levels to storage mites. Furthermore, the strong correlation between serum allergen-specific IgE levels in response to insects and the low level or complete lack of serum allergen-specific IgE in response to moulds suggest that equine allergy panels in Mediterranean areas could be modified to include only the most prevalent allergens in equine allergic diseases. However, because the population used in our study was small, further studies using healthy and allergic horses are needed to evaluate whether the equine allergy panel is adequate and will likely improve the diagnosis of allergic disease in horses.

\section{Acknowledgements}

We wish to thank the local veterinarians who sent us serum samples from their allergic patients and the owners who let us use their horses for this study. Funding, including the cost of serology testing, was provided by the Laboratorios Diavet, Leganés, Madrid, Spain. The authors wish to express their appreciation to Dr. David Senior for critically reading and revising the manuscript.

\section{References}

Baxter, C. G. and Vogelnest, L. J. (2008): Determination of threshold concentrations of multiple allergenic extracts for equine intradermal testing using normal horses in three seasons. Vet. Dermatol. 19, 305-313.

D’Amato, G., Cecchi, L., Bonini, S., Nunes, C., Annesi-Maesano, I., Behrendt, H., Licardi, G., Popov, T. and van Cauwenberge, P. (2007): Allergenic pollen and pollen allergy in Europe. Allergy 62, 976-990. 
Eder, C., Crameri, R., Mayer, C., Eicher, R., Straub, R., Gerber, H., Lazary, S. and Marti, E. (2000): Allergen-specific IgE levels against crude mould and storage mite extract and recombinant mould allergens in sera from horses affected with chronic bronchitis. Vet. Immunol. Immunopathol. 73, 241-253.

Eder, C., Curik, I., Brem, G., Crameri, R., Bodo, I., Habe, F., Lazary, S., Sölkner, J. and Marti, E. (2001): Influence of environmental and genetic factors on allergen-specific immunoglobulin-E levels in sera from Lipizzan horses. Equine Vet. J. 33, 714-720.

Frey, R., Bergvall, K. and Egenvall, A. (2008): Allergen-specific IgE in Iceland horses with bite hypersensitivity and healthy controls, assessed by FceR $1 \alpha$-based serology. Vet. Immunol. Immunopathol. 126, 102-109.

García-Mozo, H., Galán, C., Alcázar, P., Díaz, C., Nieto, D., Recio, M., Hidalgo, P., González, F., and Domínguez, E. (2010): Trends in grass pollen season in southern Spain. Aerobiologia 26, 157-169.

Grevenhof, E. M., Ducro, B., Heuven, H. C. M. and Bijma, O. (2007): Identification of environmental factors affecting the prevalence of insect bite hypersensitivity in Shetland ponies and Friesian horses in the Netherlands. Equine Vet. J. 39, 69-73.

Lebis, C., Boudeau, P. and Marzin-Keller, F. (2002): Intradermal skin tests in equine dermatology: a study of 83 horses. Equine Vet. J. 34, 666-672.

Lorch, G., Hillier, A., Kwochka, K. W., Saville, W. A., Khon, C. W. and LeRoy, E. (2001a): Comparison of immediate intradermal test reactivity with serum IgE quantitation by use of a radioallergosorbent test and two ELISA in horses with and without atopy. J. Am. Vet. Med. Assoc. 218, 1314-1322.

Lorch, G., Hillier, A., Kwochka, K. W., Saville, W. A. and LeRoy, E. (2001b): Results of intradermal tests in horses without atopy and horses with atopic dermatitis or recurrent urticaria. Am. J. Vet. Res. 62, 1051-1059.

Morgan, E. E., Miller, W. H. and Wagner, B. A. (2007): Comparison of intradermal testing and detection of allergen-specific immunoglobulin $\mathrm{E}$ in serum by enzyme-linked immunosorbent assay in horses affected with skin hypersensitivity. Vet. Immunol. Immunopathol. 120, $160-167$.

Mueller, R. S., Janda, J., Jensen-Jarolim, E., Rhyner, A. and Marti, E. (2016): Allergens in veterinary medicine. Allergy 71, 27-35.

Mueller, R. S., Jensen-Jarolim, E., Roth-Walter, F., Marti, E., Janda, J., Seida, A. A. and De Boer, D. (2018): Allergen immunotherapy in people, dogs, cats and horses - differences, similarities and research needs. Allergy 73, $1-11$.

Niedzwiedz, A., Jaworski, Z. and Kubiak, K. (2015): Serum concentration of allergen-specific IgE in horses with equine recurrent airway obstruction and healthy controls assessed by ELISA. Vet. Clin. Pathol. 44, 391-396.

Raskova, V. and Citek, J. (2013): Incidence of insect bite hypersensitivity in a small population of warmblood horse breed in the Czech Republic. J. Equine Vet. Sci. 33, 417-432.

Rendle, D. I., Durham, A. E., Wylie, C. E. and Newton, J. R. (2010): Results of intradermal testing for the investigation of atopic dermatitis and recurrent urticaria in 50 horses in the south of England. Equine Vet. Educ. 22, 616-622.

Roberts, H. A., Hurcombe, S. D. A., Hillier, A. and Lorch, D. (2014): Equine intradermal test threshold concentrations for house dust mite and storage mite allergens and identification of stable acari fauna. Vet. Dermatol. 25, 124-135.

Saridomichelakis, M. N., Marsella, R., Lee, K. W., Esch, R. E., Farmakis, R. and Koutinas, A. F. (2008): Assessment of cross-reactivity among five species of house dust and storage mites. Vet. Dermatol. 19, 67-76.

Schaffartzik, A., Hamza, E., Janda, J., Crameria, R., Marti, E. and Rhyner, C. (2012): Equine insect bite hypersensitivity: What do we know? Vet. Immunol. Immunopathol. 147, 113-126.

Scott, D. W. and Miller, W. H. (2011): Equine Dermatology. Second edition. Saunders Elsevier, Missouri, USA. 
Tahon, L., Baselgia, S., Gerber, V., Doherr, M. G., Straub, R., Robinson, N. E. and Marti, E. (2009): In vitro allergy test compared to intradermal testing in horses with recurrent airway obstruction. Vet. Immunol. Immunpathol. 127, 85-93.

Wilkołek, P. M., Pomorski, Z. J. H., Szczepanik, M. P., Adamek, Ł., Pluta, M., Gołynski, M., Rozwód, A. and Sitkowski, W. (2014): Assessment of serum levels of allergen-specific immunoglobulins E in different seasons and breeds in healthy horses. Polish J. Vet. Sci. 17, $331-337$. 